\title{
Response to the Fallon Inquiry: from the Ashworth Hospital Medical Staff
}

\author{
P. M. Abbott and J. D. Collins on behalf of the Ashworth Hospital \\ Medical Staff
}

The Fallon Inquiry into the Personality Disorder Unit at Ashworth Hospital was established in February 1997 and reported two years later (Fallon, 1999). The Inquiry was precipitated by serious allegations including those of paedophile activity on Lawrence Ward. These allegations shocked Ashworth Hospital and the nation.

The Blom-Cooper Inquiry into Ashworth Hospital (Blom-Cooper et al, 1992) described an authoritarian and anti-therapeutic regime. The hospital subsequently experienced a period of rapid change and liberalisation in response to the Blom-Cooper recommendations. Seven years on, the Fallon Inquiry team recognised that some positive therapeutic and cultural changes had occurred within the hospital following on from the Blom-Cooper Inquiry. However, they also acknowledged the part played by the liberalisation process in setting the scene for the adverse events on Lawrence Ward. In retrospect. the political pressure for the rapid implementation of the Blom-Cooper recommendations did the hospital a disservice in preventing a properly managed process of change. Large organisations with an historical emphasis on security tend to be ill equipped to deal with rapid change (Handy, 1993). Ashworth Hospital is also a clinically complex institution which cares for exceptionally challenging patients whose diverse needs many other services are unable to meet. The delicate balancing act between the requirements of high security and treatment and rehabilitation (Royal College of Psychiatrists, see pages 452-454, this issue) renders it imperative that great care is exercised in any change process.

The experience of the hospital following the Blom-Cooper Inquiry indicates the need for a considered approach to the implementation of change following the Fallon Inquiry. We agree with the College's comments concerning the importance of avoiding oscillations of emphasis between security and treatment based regimes. Proper integration of treatment and security obviates the possibility of artificial polarisation and leads to the development of a safe and secure therapeutic milieu. As clearly acknowledged by the College, it is impossible to eliminate completely the risk of adverse events in the management of mentally disordered offenders, a matter recognised in other areas of medicine (Vincent, 1997). Public recognition of this could pave the way for a wider debate as to what constitutes an acceptable level of risk within a democratic and humanitarian society.

The Fallon Inquiry Report (1999) criticised all the clinical professions within the hospital, and management systems both within and beyond the hospital. We recognise that Ashworth medical staff have been subject to serious criticism within the Fallon Report. We accept that many of these criticisms were justified. Professional isolation has been repeatedly cited as a major issue. Ashworth Hospital has been exhorted to address this issue in both inquiry reports. However, the way in which the structure and training of the national forensic psychiatric services have developed has contributed to this problem. It is not only the attitudes within Ashworth which need to change.

Like the Blom-Cooper Report, the Fallon Report offers important observations and valuable recommendations as well as others about which we would have reservations. Themes within the report pertinent particularly to Ashworth itself have been addressed within the hospital's Action Plan. These include the development of clear systems of accountability and the recruitment and retention of high calibre staff across all clinical disciplines. We appreciate the support given to Ashworth by the Secretary of State and senior figures within the National Health Service Executive. Some issues within the report have a wider relevance, such as the discussions concerning personality disorder which will feed into the wider debate on this complex subject. Of particular note to the psychiatric profession as a whole is the role of the responsible medical officer (RMO) within a 
multi-disciplinary context. The responsible medical officer has special responsibility for the overall treatment and care of detained patients. However, the extent to which this should involve the direct supervision of other professional disciplines in their day to day work (for example, nursing staff in ward searches) needs clarification. We would welcome the input of the College in this matter.

There are important questions to be asked in relation to appropriate training for consultant psychiatrists working in special hospitals. High levels of forensic expertise are essential within high security services. However, it is our view that the complexity of the special hospital patient population demands a range of specialist clinical skills in addition to forensic skills.

It is our view that the development of comprehensive services for patients who need longer term secure care requires change across the whole spectrum of current services - not just the special hospital sector. The clinical staff within special hospitals have the expertise and experience to play a key role in these service developments. We hope that the wider profession takes a fresh look at the essential but very challenging work of the high security services and plays a part in the development of reconfigured needs based services for the spectrum of challenging patients currently cared for within special hospitals. We look forward to the continuing support of the College in these endeavours as offered within the response to the Inquiry Report.

\section{References}

BLOM-COOPER, L., BROWN, M., DOLAN, R., et al (1992) Report of the Committee of Inquiry into Complaints About Ashworth Special Hospital. Cm 2028-I-II. London: HMSO.

FALLON, P., BLUGLASS, R., EDWARDS, B., et al (1999) Report of the Committee into the Personality Disorder Unit, Ashworth Special Hospital. Cm 4194-I-II. London: The Stationery Office.

HANDY, C. D. (1993) Understanding Organisations (4th edn). London: Penguin Books.

VINCENT, C. (1997) Risk, safety and the dark side of quality. British Medical Joumal, 34, 1775-1776.

*P. M. Abbott, Consultant Psychiatrist (Rehabilitation); and J. D. Collins, Consultant Forensic Psychiatrist, on behalf of the Ashworth Hospital Medical Staff, Ashworth Hospital Authority, Parkbourn, Maghull, Liverpool L31 IHW

* Correspondence

\section{CAN: Camberwell Assessment of Need}

Mike Slade, Graham Thornicroft, Linda Loftus, Michael Phelan \& Til Wykes

The Camberwell Assessment of Need (CAN) is a tried and tested approach to assessing the needs of the severely mentally ill which is suitable both for research studies and routine clinical use. Rigorously developed by staff at the Section of Community Psychiatry (PRiSM), Institute of Psychiatry, the CAN is suitable for use in primary care settings, specialist mental health teams, and social services. It will be of particular interest to care managers and mental health staff who wish to meet the legal requirement that the severely mentally ill receive a comprehensive needs assessment.

July 1999, f45.00, 144pp, Ringbound pack incl. photocopiable material, ISBN 1901242250

Available from Book Sales, Royal College of Psychiatrists, 17 Belgrave Square, London SW1X 8PG Tel +44 (0) 1712352351 (extension 146), Fax +44 (0) 1712451231 http://umw.rcpsych.ac.uk 